\title{
Optical characterization of the deep-waters of the Gulf of Mexico by in situ PAR during summer
}

\author{
Erik Coria-Monter $^{1}(\mathbb{D})$, Adolfo Gracia ${ }^{1}(\mathbb{D})$, David Alberto Salas de León ${ }^{1}$ \\ María Adela Monreal-Gómez ${ }^{1}$ \& E Elizabeth Durán-Campos ${ }^{2}$ \\ ${ }^{1}$ Instituto de Ciencias del Mar y Limnología, Unidad Académica de Ecología y Biodiversidad Acuática \\ Universidad Nacional Autónoma de México, Ciudad de México, México \\ ${ }^{2}$ Instituto de Ciencias del Mar y Limnología, Universidad Nacional Autónoma de México \\ Unidad Académica Mazatlán, Sinaloa, México \\ Corresponding author: Erik Coria-Monter (coria@cmarl.unam.mx)
}

\begin{abstract}
Phytoplankton is a sentinel group of organisms of climate change due to their capacity to respond to multiple stressors, so studies documenting the optimal optical conditions within the water column affecting their growth and production are imperative. As a contribution to this topic, this study report selected optical properties in deep-waters of the Gulf of Mexico by in situ measurements during summertime. A multidisciplinary research cruise was carried during August/September of 2018. A CTD instrument configured with underwater quantum and fluorescence sensors were used to acquire data of temperature, conductivity, depth, photosynthetically active radiation (PAR), and fluorescence of chlorophyll- $a$, which were used to determine selected optical coefficients, including the light extinction $(k)$, the compensation light intensity $\left(E_{c}\right)$, the compensation depth $\left(Z_{c}\right)$, the critical depth $\left(Z_{c r}\right)$, and the incident irradiance $\left(E_{0}\right)$. The Brunt-Väisälä frequency calculated from CTD data was used as a magnitude indicator of the water column stratification. The results showed a pycnocline located between 23 and $68 \mathrm{~m}$ depth, and favorable conditions for phytoplankton production with high values of $E_{0}$ reaching $1523.4 \mu \mathrm{mol} \mathrm{m} \mathrm{m}^{-2}, E_{c}$ values ranging from 3 to $8 \mu \mathrm{mol} \mathrm{m} \mathrm{m}^{-2} \mathrm{~s}^{-1}$, values of $Z_{c r}$ greater than $Z_{c}$ and maximum records of $k$ values of 0.06 . Based on multivariate statistical techniques, two zones were clearly defined. These results represent the first observational report on the optical properties in the deep region of the Gulf of Mexico. Studies on the ideal optical conditions for carrying out phytoplankton photosynthesis and their possible seasonal and interannual variability are essential to understand the processes that support the phytoplankton production, especially in regions that are characterized by their high biodiversity.
\end{abstract}

Keywords: optical characterization; photosynthetically active radiation; in situ measurements; phytoplankton; deep-waters; Gulf of Mexico

Phytoplankton includes a heterogeneous group of microscopic organisms, mostly autotrophic, distributed into the euphotic layer of the world's oceans. They are responsible for more than $45 \%$ of the planet's net primary production (Simon et al. 2009). Phytoplankton represents the base of the oceanic trophic webs, contributing to supporting fisheries of high commercial value in the world. It plays a fundamental role in mitigating global warming by reducing $\mathrm{CO}_{2}$ concentrations around the globe (Durán-Campos et al. 2019).
Recently, the phytoplankton has been named sentinel organisms of climate change due to their capacity to respond quickly to environmental perturbations; therefore, monitoring phytoplankton communities is essential for a full understanding of potential changes in the marine ecosystem (Bellacicco et al. 2020).

Since phytoplankton is distributed in the euphotic layer of the oceans, studies monitoring their communities are essential. Up to now, it is increasingly common to find studies that investigate the optical pro-

Corresponding editor: María Morales Covarrubias 
perties of the water column around the globe. Still, studies that analyze the bio-optical properties of the water column are important. They are focused on understanding the potential impacts of climate change, the role that phytoplankton play in the absorption and sinking of $\mathrm{CO}_{2}$ in the ocean, and mainly on the development of algorithms to improve satellite ocean color observations to map global phytoplankton distribution (Bellacicco et al. 2019, 2020, Pitarch et al. 2021). These studies also consider water column optical properties that influence the entire planktonic communities by controlling the biological radiation exposure and the availability of solar energy for photosynthesis (Coria-Monter et al. 2019a).

The optical properties that are essential for phytoplankton growth include, among others, the photosynthetically active radiation (PAR), the light extinction coefficient $(k)$, compensation depth $\left(\mathrm{Z}_{c}\right)$, critical depth $\left(\mathrm{Z}_{c r}\right)$, and compensation light intensity $\left(\mathrm{E}_{c}\right)$ (Takao et al. 2014). PAR presents seasonal and daily changes. It is also influenced by cloud cover, so this parameter is considered a more dynamic resource than nutrients. Their quantification is a key parameter to consider in studies of the phytoplankton dynamics (Köhler et al. 2017).

Optical properties have been analyzed in different domains around the globe to understand important processes and mechanisms such as the North Atlantic spring phytoplankton bloom (Siegel et al. 2002), phytoplankton photoacclimation processes (Dubinsky \& Stambler 2009), cellular physiological adjustments in response to environmental stressors like light limitation (Behrenfeld \& Boss 2014); to show conditions for phytoplankton community growth and net primary production (Coria-Monter et al. 2019a). The stratification also influences the optical properties throughout the water column, and the Brunt-Väisälä frequency depends on the vertical density gradient. It is used as a measure of the stratification in the ocean. The highest value reveals the depth of the pycnocline. It is also possible to identify the thermocline depth because the temperature in oceanic areas dominates the density.

The Gulf of Mexico (GM) is a dynamic ocean basin with a high variable topography reaching depths of $>3000 \mathrm{~m}$ at its central portion (Bryant et al. 1991) (Fig. 1a).

The gulf is a very productive area characterized by high biodiversity and very important economic activities, a reason why it has been included in the list of the Large Marine Ecosystem around the globe (Sherman \& Hempel 2009). The GM also hosts a wide diversity of pelagic fishes of high commercial and ecological value in the ecosystem, including billfishes, tunas, and sharks (Ramírez et al. 2019, Rooker et al.
2019), which is linked to the productivity in the lower trophic levels, such as the plankton. Additionally, GM has great economic importance due to the large activities of oil exploration, extraction, and transport (Door et al. 2019). It is connected with the Atlantic Ocean and the Caribbean Sea through the Florida Strait and the Yucatan Channel, so, the physical properties of the water column and ocean circulation in the region are highly dynamic, encompassing upwelling processes, fronts, and the Loop Current, which in turn originate anticyclonic or cyclonic mesoscales eddies (Vázquez de la Cerda et al. 2005, Díaz-Flores et al. 2017). These last ones appeal to support the productivity of the region, particularly the phytoplankton one (Durán-Campos et al. 2017). Moreover, in its southern portion, the GM hosts one of the largest rivers on the American continent, the Grijalva-Usumacinta system. Its high contribution of terrigenous material to the open ocean, mainly during the rainy season, could influence the optical properties of the water column due to the presence of high content of particulate organic material (Muñoz-Salinas \& Castillo 2015, Nooren et al. 2017).

Studies on the phytoplankton community in the southern region of the GM have shown that its production is closely related to mesoscale processes in the region, such as eddies, which induce local fertilization in the euphotic layer due to the transport of nutrients (Durán-Campos et al. 2017). Similar observations were made by Linacre et al. (2015), showing that the distribution patterns of picoplankton biomass in the southern GM were strongly associated with the mesoscale dynamics that modulated the surface mixed layer hydrographic conditions.

Although studies on the processes that influence the phytoplankton production and distribution in the southern GM have been previously reported (Signoret et al. 2006, Linacre et al. 2015, Durán-Campos et al. 2017), there is still a lack of information related to the optimal properties of the water column for phytoplankton photosynthesis and primary production, particularly in the deep-waters of GM. These properties include the optical characteristics of the water column like the incident irradiance levels $E_{o}, k, Z_{c}, Z_{c r}, E_{c}$. Reports on these properties are limited to the contributions of Salas de León et al. (2004) and Signoret et al. (2006), who registered the presence of optimal conditions for phytoplankton community growth and net primary production (e.g. $\mathrm{E}_{o}$ values $>1000 \mu \mathrm{mol} \mathrm{m} \mathrm{m}^{-2}$, and $Z_{c r}$ values greater than $Z_{c}$ ). They provided valuable information about the optical properties of the water column in the southern region, including the Campeche Canyon and the continental shelf. More recently, Coria-Monter et al. (2019a) evaluated the optical properties of waters of the Campeche Canyon and Campeche Bank, southern GM, 


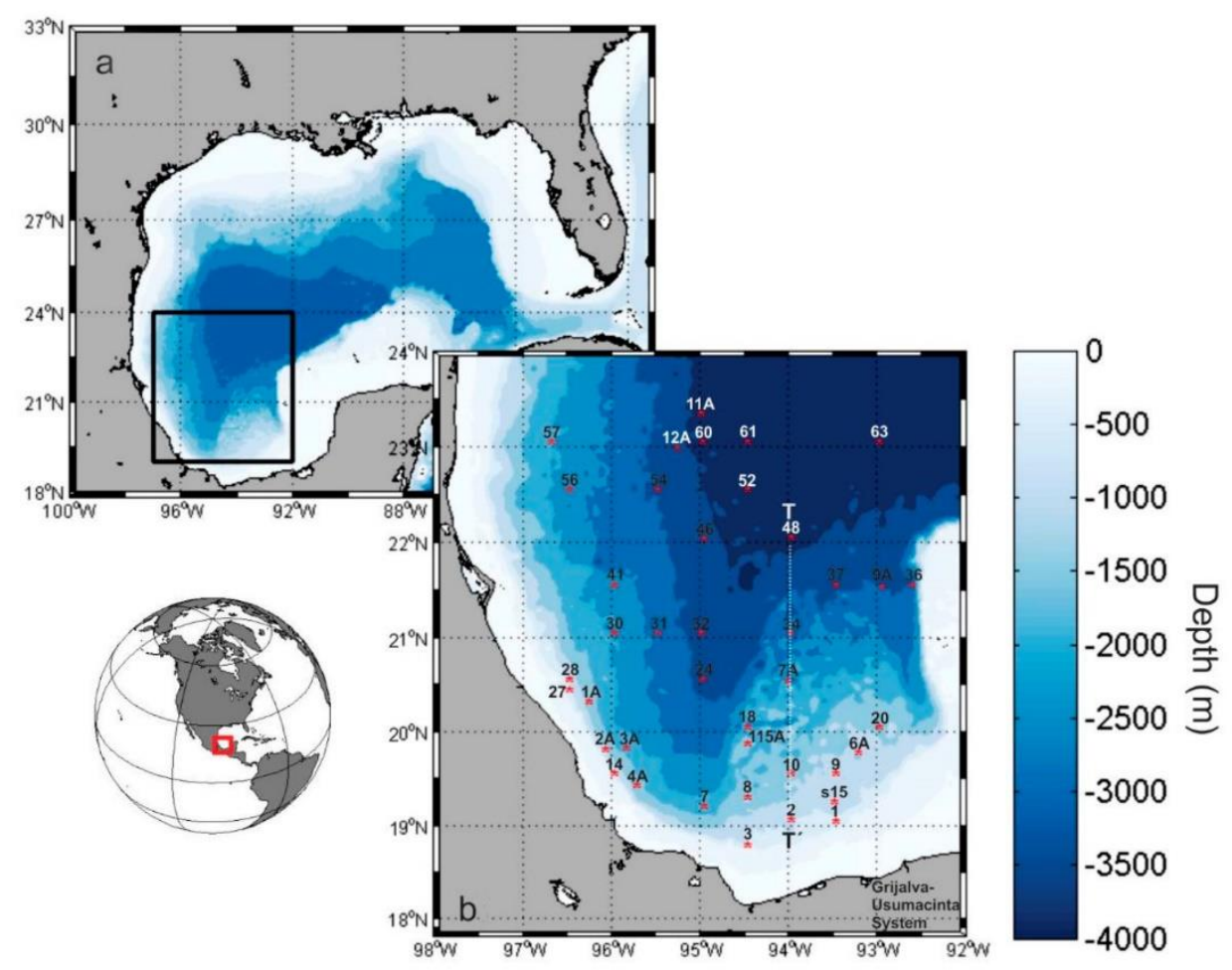

Figure 1. Study area. a) Gulf of Mexico, b) hydrographic stations represented by *symbols. T-T' represent the transect used for Brunt-Väisälä frequency calculation. The bathymetry is expressed in meters.

by in situ photosynthetically active radiation (PAR) measurements revealing an interesting contrast between the two areas, but also indicated the presence of optimal conditions for phytoplankton community growth and net primary production. So, studies aiming at the optical characterization of the water column are imperative to assess the phytoplankton growth rates and play a significant role in the generation of light transmission models in the ocean, which are also important for ocean productivity studies based on satellite observations (Takao et al. 2014).

Even though the National Autonomous University of Mexico (UNAM Spanish acronym) began an uninterrupted monitoring program of the Mexican waters of the GM in the 1980s, the vast majority of the oceanographic cruises carried out to date have focused on the continental shelf area. Therefore, direct observations from the deep waters of the GM are still scarce. This study aims to report selected optical properties values in a region of the GM within a depth range of 187-3735 m, obtained by in situ highresolution spatial measurements, including conductivity, temperature, fluorescence, and PAR levels. We hypothesize that there would be changes in the optical properties of the water column due to the wide depth range in the region. To our best knowledge, the values presented here represent the first observational report of these properties in the deep region of the GM.
We gathered high-resolution records (both horizontal and vertical) during the multidisciplinary research cruise SOGOM-04, carried on board the R/V Justo Sierra of the UNAM from August 29 to September 20 of 2018, covering a grid of 40 hydrographic stations, which included the deep region of the GM (Fig. 1b). Conductivity, temperature, pressure, PAR, and fluorescence levels at all stations were measured with a SeaBird 9 plus CTD attached to a rosette system (General Oceanics, Inc.) configured with an underwater quantum sensor (Sea-Bird Scientific's) and a fluorescence sensor (ECO-Wet Labs), previously calibrated by the manufacturers. The CTD casts were made from the illuminated side of the ship to avoid their shadow and the reflection of the hull to obtain good quality data. The CTD casts extended almost to the bottom at a rate of $1 \mathrm{~m} \mathrm{~s}^{-1}$, acquiring data at $24 \mathrm{~Hz}$ while the ship maintained its position on the station. Sensitivity in temperature and conductivity were $0.005^{\circ} \mathrm{C}$ and $0.0005 \mathrm{~s} \mathrm{~m}^{-1}$, respectively.

The CTD data were primarily processed with the routines and subroutines recommended by the manufacturer (SBE Data Processing V.7.26.7) and finally averaged to $1 \mathrm{dbar}$. Then, conservative temperature $(\Theta$, $\left.{ }^{\circ} \mathrm{C}\right)$, absolute salinity $\left(\mathrm{S}_{\mathrm{A}}, \mathrm{g} \mathrm{kg}^{-1}\right)$ and density $\left(\sigma_{\Theta} \mathrm{kg} \mathrm{m}^{-3}\right)$ values were calculated of in situ temperature, and practical salinity was done according to the thermody- 
namic equation of seawater-2010 (TEOS-10) (IOC et al. 2010). The Brunt-Väisälä or buoyancy frequency $(N)$ which is a measure of stratification throughout the water column is given by $N^{2}=-\frac{g}{\rho_{0}} \frac{\partial \sigma_{T}}{\partial z}$ (Pond \& Pickard 1983); where $g$ is the acceleration due to gravity, $\rho_{o}$ is a mean density in the water column, and $\frac{\partial \sigma_{T}}{\partial z}$ is the vertical density gradient. The Brunt-Väisälä frequency in the upper $150 \mathrm{~m}$ layer was calculated from CTD cast measurements to analyze the mixed layer depth. The phytoplankton biomass, expressed as chlorophyll- $a$ concentration $\left(\mathrm{mg} \mathrm{m}^{-3}\right)$, was estimated following the nominal conversion factor provided by the manufacturer, based on in situ fluorescence.

Selected optical properties along the water column were calculated based on the in situ measurements during the research expedition. We estimated the average light extinction coefficient in the water column (k) following Lalli \& Parsons (2006) and Falkowski \& Raven (2007):

$$
k=\frac{\ln \left(E_{0}\right)-\ln \left(E_{D}\right)}{z}
$$

where $E_{0}$ is surface radiation, and $E_{D}$ is radiation at depth $z$, the last defined as the limit of the euphotic zone.

The compensation depth $\left(Z_{c}\right)$ is the depth at which gross photosynthetic carbon fixation balances the phytoplankton respiratory losses, and represents the lower limit of the euphotic layer, and was calculated following the expression of Falkowski \& Raven (2007):

$$
Z_{c}=\frac{\ln \left(E_{0}\right)-\ln \left(E_{c}\right)}{k}
$$

The equipment measures surface radiation $E_{0}$, and $k$ is calculated with equation (1). $E_{c}$ is defined as the compensation light intensity; in our particular case, these values ranged from 3 to $8 \mu \mathrm{mol} \mathrm{m} \mathrm{m}^{-2} \mathrm{~s}^{-1}$ (see Table 1 below), agreeing with typical values reported in other domains (e.g. 1 to $10 \mu \mathrm{mol} \mathrm{m} \mathrm{m}^{-2} \mathrm{~s}^{-1}$ ) (Lalli \& Parsons 2006). The symbol $I$, which is sometimes used in previous papers to denote irradiance, was not used here since it has been more recently adopted to represent radiation intensity, which is the flux of radiant energy per unit solid angle in a specified direction (Falkowski \& Raven 2007).

The critical depth $\left(Z_{c r}\right)$, which represents the depth at which the photosynthesis is equal to the respiration, was calculated with the expression:

$$
Z_{c r}=\frac{0.5 E_{0}}{E_{c} k}
$$

where $E_{0}$ is the incident irradiance (here multiplied by 0.5 based on $50 \%$ photosynthetic active radiance.
According to Coria-Monter et al. (2019a)), $E_{c}$ is the irradiance at the depth that gross photosynthesis equals respiration, and $k$ is the extinction coefficient.

Fluorescence values were transformed to chlorophyll- $a$ concentration $\left(\mathrm{mg} \mathrm{m}^{-3}\right)$ and were then integrated along the euphotic layer calculated for each hydrographic station (Table 1) according to the expression:

$$
\operatorname{Chla}\left(m g m^{-2}\right)=\sum_{i=1}^{n}(\text { Chla })_{i}(\Delta z)_{i}
$$

where Chl- $a\left(\mathrm{mg} \mathrm{m}^{-2}\right)$ is the chlorophyll- $a$ vertically integrated, while $n$ is the depth of integration, in our case, the euphotic layer.

Finally, the depth of maximum vertical temperature gradient $(\partial T / \partial z)$ was used to estimate the mixed layer depth, which was also obtained from the Brunt-Väisälä frequency along the $\mathrm{T}-\mathrm{T}^{\prime}$ transect (Fig. 1b), in the upper $150 \mathrm{~m}$ layer. Based on the calculation results, we construct a data set subject to different multivariate statistical techniques. First, to test statistical significance, correlations analyses were performed between the other variables obtained in this study. Second, a principal component analysis (PCA) was applied. PCA analyzes a data set representing observations described by several dependent variables, which are, in general, inter-correlated to extract information from the data set and express this information as a set of new orthogonal variables named as principal components (Abdi \& Williams 2010). Finally, an agglomerative cluster analysis (Clarke 1993) was done based on using a BrayCurtis similarity index to determine the similarities of stations.

The calculations presented in this study represents valuable dataset addition for the southern GM to 1) understand phytoplankton primary production rates, 2) understand phytoplankton dynamics to improve estimations of carbon export and sequestration, 3) understand phytoplankton photo acclimation processes, 4) for the generation, or improvement, of algorithms of ocean color satellite observations, and 5) for the generation of models related to the impacts of climate change in the phytoplankton communities.

The spatial high-resolution in situ measurements allowed us to calculate selected optical properties of deep-waters of the GM. Table 1 summarized the values obtained for each station.

The maximum value of the $N^{2}\left(18 \times 10^{-4} \mathrm{~s}^{-2}\right)$ and the $\mathrm{T}-\mathrm{T}^{\prime}$ transect corresponding to the pycnocline was between 35 and $65 \mathrm{~m}$ depth, which was shallower at station 7A (Fig. 2). In the study area, the mixed layer depth presents seasonal variations. During winter, it is located deeper than $120 \mathrm{~m}$ (Damien et al. 2018) due to low insolation and strong northern winds. Results from 
Table 1. Selected optical properties of the deep waters of the Gulf of Mexico during the summer. St: station, Lat: latitude $\left({ }^{\circ} \mathrm{N}\right)$, Lon: longitude $\left({ }^{\circ} \mathrm{W}\right)$, Z: total depth $(\mathrm{m})$, EL: euphotic layer depth $(\mathrm{m})$, k: average extinction coefficient, $E_{0}$ : incident irradiance $\left(\mu \mathrm{mol} \mathrm{m} \mathrm{m}^{-2} \mathrm{~s}^{-1}\right), \mathrm{E}_{c}$ : compensation light intensity $\left(\mu \mathrm{mol} \mathrm{m} \mathrm{m}^{-2} \mathrm{~s}^{-1}\right), \mathrm{Z}_{c}$ : compensation depth $(\mathrm{m}), \mathrm{Z}_{c}$ : critical depth (m), ML: mixed layer depth (m), ICHLA: integrated chlorophyll- $a$ values $\left(\mathrm{mg} \mathrm{m}^{-2}\right)$, DCM: maximum chlorophyll- $a$ depth (m), MCHLA: chlorophyll- $a$ at the maximum $\left(\mathrm{mg} \mathrm{m}^{-3}\right)$, T: temperature $\left({ }^{\circ} \mathrm{C}\right)$ at the chlorophyll- $a$ maximum.

\begin{tabular}{|c|c|c|c|c|c|c|c|c|c|c|c|c|c|c|}
\hline St & Lat & Lon & $\mathrm{Z}$ & EL & $\mathrm{k}$ & $E_{0}$ & $\mathrm{E} c$ & $\mathrm{Zc}$ & $\mathrm{Zcr}$ & ML & ICHLA & DCM & MCHLA & $\mathrm{T}$ \\
\hline 1 & 19 & -93.5 & 454 & 70 & 0.02 & 125.4 & 5 & 88.2 & 150 & 28.3 & 1.49 & 86.4 & 0.57 & 22.0 \\
\hline $1 \mathrm{~A}$ & 20.3 & -96.3 & 1016 & 101 & 0.01 & 110 & 4 & 92.6 & 136 & 48.2 & 1.26 & 90.4 & 0.61 & 21.9 \\
\hline 2 & 19 & -94 & 668 & 68 & 0.00 & 152.6 & 4 & 120 & 125 & 43.2 & 1.32 & 88.4 & 0.51 & 21.7 \\
\hline $2 \mathrm{~A}$ & 19.8 & -96.1 & 784 & 114 & 0.01 & 151 & 5 & 143 & 241 & 26.3 & 1.32 & 77.5 & 0.47 & 21.9 \\
\hline 3 & 18.7 & -94.5 & 1278 & 103 & 0.04 & 103.3 & 4 & 387 & 666 & 34.4 & 1.24 & 89.4 & 0.5 & 21.0 \\
\hline $3 \mathrm{~A}$ & 19.8 & -95.9 & 1526 & 93 & 0.00 & 41 & 3 & 421 & 645 & 36.3 & 1.22 & 90.4 & 0.67 & 21.8 \\
\hline $4 \mathrm{~A}$ & 19.4 & -95.8 & 1150 & 71 & 0.01 & 54.4 & 4 & 302 & 478 & 31.3 & 1.28 & 87.4 & 0.61 & 21.8 \\
\hline $6 \mathrm{~A}$ & 19.7 & -93.2 & 966 & 95 & 0.01 & 125.3 & 4 & 220 & 395 & 65.1 & 1.24 & 84.4 & 0.42 & 23.3 \\
\hline 7 & 19.2 & -95 & 1721 & 111 & 0.00 & 241.8 & 5 & 313 & 440 & 42.2 & 1.2 & 98.3 & 0.46 & 21.8 \\
\hline $7 \mathrm{~A}$ & 20.5 & -94 & 1871 & 81 & 0.00 & 360.8 & 6 & 307 & 571 & 34.3 & 1.19 & 56.6 & 0.61 & 21.7 \\
\hline 8 & 19.3 & -94.5 & 1255 & 125 & 0.01 & 618.1 & 6 & 191 & 353 & 46.2 & 1.23 & 94.4 & 0.43 & 25.4 \\
\hline 9 & 19.5 & -93.5 & 686 & 108 & 0.02 & 1034 & 3 & 181 & 388 & 37.3 & 1.35 & 78.5 & 0.58 & 22.2 \\
\hline $9 \mathrm{~A}$ & 21.5 & -93 & 2921 & 89 & 0.00 & 395.6 & 6 & 492 & 909 & 44.2 & 1.17 & 64.5 & 0.66 & 21.6 \\
\hline 10 & 19.5 & -94 & 1158 & 102 & 0.01 & 173.2 & 4 & 232 & 435 & 43.2 & 1.24 & 86.4 & 0.51 & 21.0 \\
\hline $115 \mathrm{~A}$ & 19.8 & -94.5 & 1422 & 98 & 0.01 & 272.7 & 5 & 234 & 421 & 43.2 & 1.24 & 84.4 & 0.62 & 25.5 \\
\hline $11 \mathrm{~A}$ & 23.3 & -95 & 3592 & 104 & 0.00 & 78.3 & 4 & 410 & 653 & 68.1 & 1.03 & 68.5 & 0.58 & 25.6 \\
\hline $12 \mathrm{~A}$ & 22.9 & -95.3 & 3225 & 104 & 0.00 & 715.6 & 6 & 472 & 887 & 50.2 & 1.02 & 99.3 & 0.34 & 22.3 \\
\hline 14 & 19.5 & -96 & 187 & 69 & 0.06 & 987.2 & 7 & 22 & 40.1 & 23.4 & 1.07 & 57.6 & 0.79 & 22.6 \\
\hline 18 & 20 & -94.5 & 2243 & 118 & 0.00 & 1163 & 5 & 404 & 991 & 41.2 & 1.19 & 75.5 & 0.85 & 21.2 \\
\hline 20 & 20 & -93 & 1309 & 96 & 0.01 & 573.5 & 6 & 192 & 346 & 46.2 & 1.23 & 65.5 & 0.42 & 23.3 \\
\hline 24 & 20.5 & -95 & 3100 & 67 & 0.00 & 111.9 & 4 & 69 & 118 & 42.2 & 1.16 & 71.5 & 0.6 & 21.4 \\
\hline 27 & 20.4 & -96.5 & 378 & 132 & 0.03 & 1523 & 7 & 458 & 987 & 43.2 & 1.58 & 89.4 & 0.58 & 22.0 \\
\hline 28 & 20.5 & -96.5 & 596 & 117 & 0.02 & 427.8 & 4 & 127 & 269 & 37.3 & 1.4 & 98.3 & 0.53 & 21.9 \\
\hline 30 & 21 & -96 & 2184 & 107 & 0.00 & 368.4 & 6 & 341 & 593 & 45.2 & 1.14 & 100 & 0.39 & 23.2 \\
\hline 31 & 21 & -95.5 & 2722 & 143 & 0.00 & 761.8 & 6 & 414 & 718 & 46.2 & 1.13 & 95.3 & 0.45 & 22.8 \\
\hline 32 & 21 & -95 & 3178 & 121 & 0.00 & 970.2 & 7 & 445 & 824 & 41.2 & 1.13 & 79.4 & 0.58 & 23.0 \\
\hline 34 & 21 & -94 & 3100 & 104 & 0.00 & 336.3 & 3 & 462 & 829 & 46.2 & 1.17 & 74.5 & 0.49 & 21.4 \\
\hline 36 & 21.5 & -92.6 & 2933 & 100 & 0.00 & 669.7 & 6 & 455 & 860 & 42.2 & 1.16 & 68.5 & 0.58 & 21.5 \\
\hline 37 & 21.5 & -93.5 & 3159 & 94 & 0.00 & 626.3 & 6 & 492 & 948 & 39.3 & 1.15 & 87.4 & 0.38 & 20.9 \\
\hline 41 & 21.5 & -96 & 2437 & 137 & 0.00 & 80.1 & 5 & 510 & 776 & 37.3 & 1.14 & 115 & 0.45 & 24.2 \\
\hline 46 & 22 & -95 & 3364 & 107 & 0.00 & 148.7 & 4 & 80 & 127 & 42.2 & 1.1 & 93.3 & 0.33 & 23.2 \\
\hline 48 & 22 & -94 & 3562 & 110 & 0.00 & 342.8 & 5 & 357 & 581 & 60.1 & 1.08 & 79.4 & 0.3 & 23.3 \\
\hline 52 & 22.5 & -94.5 & 3673 & 80 & 0.00 & 32.6 & 3 & 107 & 155 & 52.2 & 1.01 & 82.4 & 0.51 & 23.2 \\
\hline 54 & 22.5 & -95.5 & 3006 & 128 & 0.00 & 129 & 5 & 658 & 1091 & 44.2 & 1 & 89.4 & 0.38 & 23.1 \\
\hline 56 & 22.5 & -96.5 & 2220 & 109 & 0.00 & 81.4 & 4 & 479 & 711 & 44.2 & 0.97 & 108 & 0.28 & 22.9 \\
\hline 57 & 23 & -96.7 & 1795 & 154 & 0.01 & 1066 & 7 & 237 & 445 & 45.2 & 1 & 105 & 0.3 & 24.2 \\
\hline 60 & 23 & -95 & 3574 & 120 & 0.00 & 1445 & 7 & 470 & 873 & 48.2 & 1.02 & 94.3 & 0.34 & 27.0 \\
\hline 61 & 23 & -94.5 & 3730 & 94 & 0.00 & 524.6 & 6 & 283 & 566 & 44.2 & 1.03 & 67.5 & 0.31 & 29.4 \\
\hline 63 & 23 & -93 & 3735 & 99 & 0.00 & 159.8 & 5 & 375 & 645 & 50.2 & 1.04 & 90.4 & 0.3 & 23.8 \\
\hline s15 & 19.2 & -93.5 & 748 & 96 & 0.01 & 613 & 8 & 94.6 & 104 & 40.3 & 1.29 & 83.4 & 0.57 & 21.9 \\
\hline
\end{tabular}

Brunt-Väisälä frequency show that in summer, the mixed layer depth ranged from 23 to $68 \mathrm{~m}$, with high stratification below it, which agree with that reported by Salas de León et al. (2004). The mixed layer depth obtained based on the vertical temperature gradient coincided with that calculated using the Brunt-Väisälä frequency, allowing us to conclude that the density is dominated by temperature in this region.
Values of $k$ are essential for the phytoplankton community in any marine ecosystem. In this study, these values reached maximum records of 0.06 . Values of $k$ ranging from 0.03 to $0.14 \mathrm{~m}^{-1}$ have been previously reported in the literature (Lalli \& Parsons 2006), comparable with our observations. Similar observations were reported by Salas de León et al. (2004), 


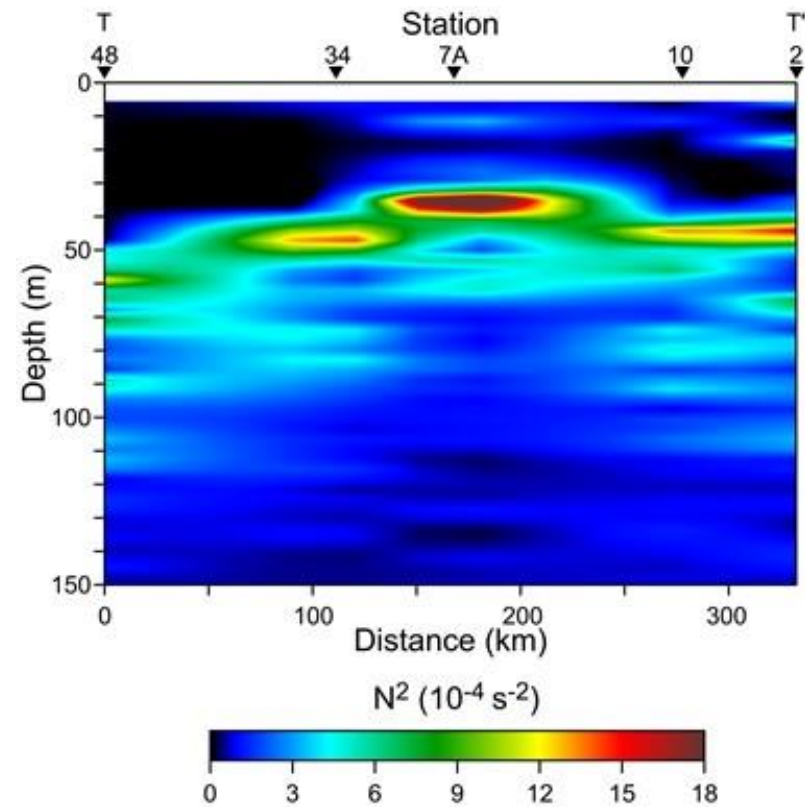

Figure 2. Brunt-Väisälä frequency along the $T-T^{\prime}$ transect (showed in Fig. 1), in the upper $150 \mathrm{~m}$ layer.

who found $k$ mean values of 0.05 for waters of the southern GM, and by Coria-Monter et al. (2019a), who found values in the same order of magnitude. As values of $k$ are affected by the amount of chlorophyll contained in the phytoplankton (Falwowski \& Raven 2007), this value has a wide variation according to the latitudinal gradient. For example, in polar areas, it is equal to 0.1. Strictly speaking, $k$ varies seasonally, and this variability is caused mostly by variations of phytoplankton concentrations (Obata et al. 1996).

The values of incident irradiance $\left(E_{0}\right)$ obtained in this study ranged from 32.6 to $1523.4 \mu \mathrm{mol} \mathrm{m} \mathrm{m}^{-2} \mathrm{~s}^{-1}$. Values of $E_{0}$ depend on the time of day when observations are complete due to the angle of the sun; on a sunny day, values of $>1000 \mu \mathrm{mol} \mathrm{m} \mathrm{m}^{-2} \mathrm{~s}^{-1}$ can be expected (Kirk 2011) in agreement with our observations. The values presented in this study also coincide with those reported by Salas de León et al. (2004) for waters in the southern GM, who registered mean values of $695 \mu \mathrm{mol} \mathrm{m} \mathrm{m}^{-2} \mathrm{~s}^{-1}$.

Values of $Z_{c}$ and $Z_{c r}$ have a pivotal role in phytoplankton growth. When $Z_{c}$ is shallower than $Z_{c r}$, optimal conditions for phytoplankton growth are present due to the growth rate exceeds the vertical mixing rate (Huisman et al. 1999). This study showed that conditions are optimal for phytoplankton growth and net primary production since $Z_{c r}$ was much greater than $Z_{c}$. Then this net primary production is represented as the organic carbon produced by photosynthesis; it is accessible to higher trophic levels (Falkowski \& Raven 2007). Few studies of the growth-irradiance relationship exist in the scientific literature to estimate key parameters such as $Z_{c r}$. For the case of environments, such as the Xiangxi Bay of the Three Gorges Reservoir (China), Köhler et al. (2017) estimated values of $Z_{c r}$ of $45 \mathrm{~m}$, while in the Bay of La Paz (southern Gulf of California, Mexico), Coria-Monter et al. (2019b) reported values of $Z_{c r}$ of only $21 \mathrm{~m}$, which were much lower than those observed in this study.

The maximum chlorophyll- $a$ values in this study presented a range of 0.28 to $0.85 \mathrm{mg} \mathrm{m}^{-3}$ agreeing with previous reports for summertime in the southern region of the gulf. Salas de Leon et al. (2004) reported values from 0.21 to $0.32 \mathrm{mg} \mathrm{m}^{-3}$, whereas Signoret et al. (2006) registered values from 0.02 to $0.45 \mathrm{mg} \mathrm{m}^{-3}$. In all stations, the peak was deep $(>50 \mathrm{~m})$ associated with the limit of the euphotic layer, defined as the limit of the $1 \%$ of incident irradiance at the surface. This condition was previously documented for the Campeche Canyon, southern GM, where deep chlorophyll- $a$ maximum was related to the limit of the euphotic layer in the summer season. A taxonomic composition dominated by coccolithophores characterized it. In contrast, the surface peaks and those above the thermocline were dominated by diatoms (Durán-Campos et al. 2017), which could be the case for our particular observations. Photosynthesis in the water column mainly takes place in the euphotic layer near the surface. At the bottom of the euphotic layer, the downward PAR irradiance decreased to $1 \%$ of its value just below the surface. The integrated chlorophyll- $a$ values calculated in this study showed a range of 0.97 to $1.58 \mathrm{mg} \mathrm{m}^{-2}$, similar to those reported by Salas de León et al. (2004). The chlorophyll- $a$ values in the southern GM present a clear seasonal variability related to the atmospheric and hydrographic forcing factors occurring in the region. For example, during the winter season, when strong winds are present (locally known as "Nortes"), it was reported that the mixing along the water column is intense, resulting in surface values of chlorophyll- $a$ of $1.45 \mathrm{mg} \mathrm{m}^{-3}$ (Torres-Martínez et al. 2020).

The results of the correlation tests showed direct and significant values. For example, values of $R=0.42$ and $P=0.0006$ were obtained between the temperature and the chlorophyll- $a$ concentrations. In contrast, $R=0.52$ and $P=0.0004$ were obtained between the euphotic layer depth and the maximum chlorophyll- $a$ depth. The PCA analysis grouped the hydrographic stations into two large regions (Fig. 3a). Interestingly, the stations of zone A included the stations between a range from 187 to $2000 \mathrm{~m}$ depth, whereas zone B included the stations delimited by the isobath $>2000 \mathrm{~m}$. This analysis also showed that the stations of zone A were closely related to the chlorophyll- $a$ values. In contrast, the zone B stations were related to the total depth, the mixed layer 

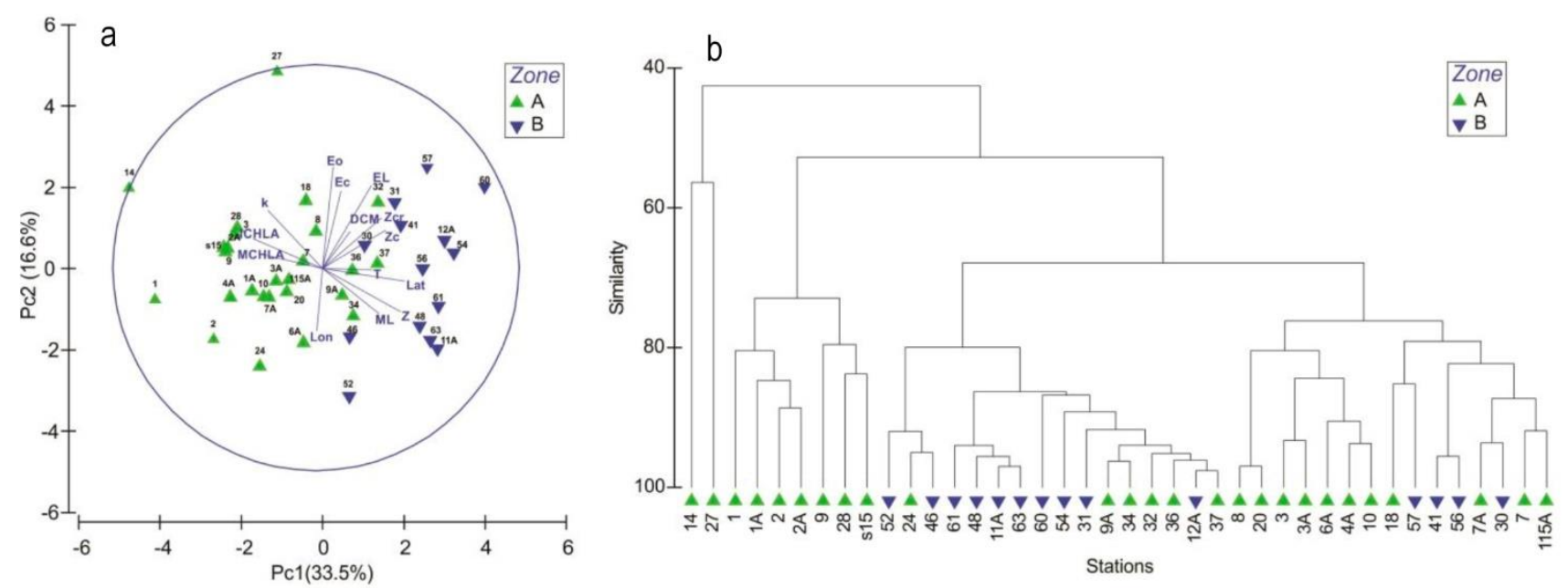

Figure 3. a) Principal component analysis (PCA), b) Bray-Curtis similarity cluster analysis. The abbreviations are referred in the Table 1 caption.

depth, the compensation depth, and the critical depth. The cluster analysis confirmed the patterns observed in the PCA, showing a clear separation of the stations according to those zones where the optical variables had an influence (Fig. 3b).

To our best knowledge, the values presented here represent the first observational report on the optical properties in the euphotic layer on deep-waters of the GM. Consequently, no data exists in the scientific literature that could compare with other seasons because the available information is limited to the summertime in the southern region, mainly in the Campeche Canyon and Campeche Bank. However, there must be important seasonal variations concerning the values presented here because the region is highly dynamic. The presence of several hydrodynamics processes and strong winds modify the water column in terms of their hydrographic properties and produce mixing with the subsequent resuspension of particles and organic matter. An additional source of variability of registered optical properties is the recurrence of hurricanes, potentially impacting the study area every year (Rojo-Garibaldi et al. 2016). Another source of variability is naturally the seasonal changes; for example, it is well known that in spring, $Z_{c}$ is generally increasing rapidly due to the effects of the increasing day length and solar elevation on $E_{0}$ values (Nelson \& Smith 1991). An additional source of these parameters variability is the extension of the GM, where a significant change in the angle of the sun would be expected due to latitude variation. Thus, analysis of seasonal variation of these parameters in the deep region of the GM by in situ observations poses important challenges due to the high costs involved in ship time.

Nonetheless, its study is essential for developing models of the optimal conditions for phytoplankton production and growth. To date, most of the phytoplankton global distribution knowledge and their seasonal variability come mainly from satellite observations (Laiolo et al. 2021). Then the quantification of the optical properties of the water column, as presented here, are key parameters for characterizing both global and regional maps of chlorophyll- $a$ concentration and primary production using remote sensing products. All marine life virtually depends on the phytoplankton structure. So, studies on the favorable optical conditions for phytoplankton photosynthesis and their possible seasonal and interannual variability will be imperative to understand the processes that support the phytoplankton production, especially in regions that have been characterized as hot-spots of biodiversity, such as the GM.

\section{ACKNOWLEDGEMENTS}

SOGOM cruises were funded by the Mexican National Council for Science and Technology - Mexican Ministry of Energy - Hydrocarbon Fund, project 201441 as part of the Gulf of Mexico Research Consortium (CIGoM) due to PEMEX's specific request to the Hydrocarbon Fund to address the environmental effects of oil spills in the Gulf of Mexico. We thank the participants of the research cruise, including the captains and crew of the $\mathrm{R} / \mathrm{V}$ Justo Sierra of the UNAM. We also appreciate verymuch the helpful comments of two anonymous 
reviewers that certainly improved the manuscript. We also thank Jorge Castro for enhancing the quality of the figures.

\section{REFERENCES}

Abdi, H. \& Williams, L.J. 2010. Principal component analysis. WIREs Computational Statistics, 2: 433-459.

Bellacicco, M., Cornec, M., Organelli, E., Brewin, R.J.W., Neukermans, G., Volpe, G., et al. 2019. Global variability of optical backscattering by non-algal particles from a Biogeochemical-Argo data set. Geophysical Research Letters, 46: 9767-9776.

Bellacicco, M., Pitarch, J., Organelli, E., MartinezVicente, V., Volpe, G. \& Salvatorre, M. 2020. Improving the retrieval of carbon-based phytoplankton biomass from Satellite Ocean Colour Observations. Remote Sensing, 12: 3640.

Behrenfeld, M.J. \& Boss, E. 2014. Resurrecting the ecological underpinnings of ocean plankton blooms. Annual Review of Marine Science, 6: 167-194.

Bryant, W.R., Lugo, J., Cordova, C. \& Salvador, A. 1991. Physiography and bathymetry. In: Salvador, A. (Ed.). The Gulf of Mexico. The Geological Society of America, Boulder, pp. 13-30.

Clarke, K.R. 1993. Non-parametric multivariate analyses of changes in community structure. Australian Journal of Ecology, 18: 117-143.

Coria-Monter, E., Monreal-Gómez, M.A., Salas de León, D.A. \& Durán-Campos, E. 2019b. Bio-optical characterization of the waters of the Bay of La Paz, southern Gulf of California, during late spring 2004. Revista de Biología Marina y Oceanografía, 54: 343-349.

Coria-Monter, E., Salas de León, D.A., Monreal-Gómez, M.A. \& Durán-Campos, E. 2019a. Optical properties of the waters of the southern Gulf of Mexico during summer. Latin American Journal of Aquatic Research, 47: 568-574.

Damien, P., Pasqueron de Fommervault, O., Sheinbaum, J., Jouanno, J., Camacho-Ibar, V.F. \& Duteil, O. 2018. Partitioning of the open waters of the Gulf of Mexico based on the seasonal and interannual variability of chlorophyll concentration. Journal of Geophysical Research: Oceans, 123: 2592-2614.

Díaz-Flores, M.A., Salas de León, D.A. \& MonrealGómez, M.A. 2017. Origin and evolution of cyclonic eddy of the Bay of Campeche, Gulf of Mexico. Revista de Biologia Marina y Oceanografia, 52: 441-450.

Dorr, B.S., Hanson-Dorr, K.C., Assadi-Porter, F.M., Selen, E.S., Healy, K.A. \& Horak, K.E. 2019. Effects of repeated sublethal external exposure to deep water horizon oil on the avian metabolome. Scientific Reports, 9: 371 .
Dubinsky, Z. \& Stambler, N. 2009. Photoacclimation processes in phytoplankton: mechanisms, consequences, and applications. Aquatic Microbial Ecology, 56: 163176.

Durán-Campos, E., Monreal-Gómez, M.A., Salas de León, D.A. \& Coria-Monter, E. 2019. Impact of a dipole on the phytoplankton community in a semienclosed basin of the southern Gulf of California, Mexico. Oceanologia, 61: 331-340.

Durán-Campos, E., Salas de León, D.A., Monreal-Gómez, M.A. \& Coria-Monter, E. 2017. Patterns of chlorophylla distribution linked to mesoscale structures in two contrasting areas Campeche Canyon and Bank, Southern Gulf of Mexico. Journal of Sea Research, 123: $30-38$.

Falkowski, P.G. \& Raven, A. 2007. Aquatic photosynthesis. Princeton University Press, New Jersey.

Huisman, J., Van Oostveen, P. \& Weissing, F.J. 1999. Critical depth and critical turbulence: two different mechanisms for the development of phytoplankton blooms. Limnology and Oceanography, 44: 17811787.

IOC, SCOR \& IAPSO. 2010. The international thermodynamic equation of seawater-2010. Calculation and use of thermodynamic properties. Intergovernmental Oceanographic Commission. Manual, and Guides 56. UNESCO, Paris.

Kirk, J.T.O. 2011. Light and photosynthesis in aquatic ecosystems. Cambridge University Press, New York.

Köhler, J., Wang, L., Guislain, A. \& Shatwell, T. 2017. Influence of vertical mixing on light-dependency of phytoplankton growth. Limnology and Oceanography, 63: 1156-1167.

Laiolo, L., Matear, R., Soja-Wozniak, M., Suggett, D.J., Hughes, D.J., Baird, M.E. \& Doblin, M.A. 2021. Modelling the impact of phytoplankton cell size and abundance on inherent optical properties (IOPs) and a remotely sensed chlorophyll-a product. Journal of Marine Systems, 213: 103460.

Lalli, C.M. \& Parsons, T.R. 2006. Biological oceanography, an introduction. Elsevier, Amsterdam.

Linacre, L., Lara-Lara, R., Camacho-Ibar, V., Herguera, J.C., Bazán-Guzmán, C. \& Ferreira-Bartrina, V. 2015. Distribution pattern of picoplankton carbon biomass linked to mesoscale dynamics in the southern Gulf of Mexico during winter conditions. Deep-Sea Research Part I, 106: 55-67.

Muñoz-Salinas, E. \& Castillo, M. 2015. Streamflow and sediment load assessment from 1950 to 2006 in the Usumacinta and Grijalva rivers (Southern Mexico) and the influence of ENSO. Catena, 127: 270-278. 
Nelson, D.M. \& Smith Jr., W.O. 1991. Sverdrup revisited: critical depths, maximum chlorophyll levels, and the control Southern Ocean productivity by the irradiancemixing regime. Limnology and Oceanography, 36: 1650-1661.

Nooren, K., Hoek, W.Z., Winkels, T., Huizinga, A., der Plicht, H.V., Van Dam, R.L., et al. 2017. The Usumacinta-Grijalva beach-ridge plain in southern Mexico: a high-resolution archive of river discharge and precipitation. Earth Surface Dynamics, 5: 529556.

Obata, A., Ishizaka, J. \& Endoh, M. 1996. Global verification of critical depth theory for phytoplankton bloom with climatological in situ temperature and satellite ocean color data. Journal of Geophysical Research, 101: 20657-20667.

Pond, S. \& Pickard, G.L. 1983. Introductory dynamical oceanography. Pergamon Press, Oxford.

Pitarch, J., Bellacicco, M., Marullo, S. \& Van der Woerd, H. 2021. Global maps of Forel-Ule index, hue angle, and Secchi disk depth derived from 21 years of monthly ESA Ocean Colour Climate Change Initiative data. Earth System Science Data, 13: 481-490.

Ramírez, J.M., Vázquez-Bader, A.R. \& Gracia, A. 2019. Ichthyofaunal list of the continental slope of the southern Gulf of Mexico. Zookeys, 846: 117-132.

Rojo-Garibaldi, B., Salas de León, D.A., Sánchez, N.L. \& Monreal-Gómez, M.A. 2016. Hurricanes in the Gulf of Mexico and the Caribbean Sea and their relationship with sunspots. Journal of Atmospheric and SolarTerrestria Physics, 148: 48-52.

Rooker, J.R., Dance, M.A., Wells, R.J.D., Ajemian, M.J., Block, B.A., Castleton, M.R., et al. 2019. Population connectivity of pelagic megafauna in the CubaMexico-United States triangle. Scientific Reports, 9: 1663.

Salas de León, D.A., Monreal-Gómez, M.A., Signoret, M. \& Aldeco-Ramírez, J. 2004. Anticyclonic-cyclonic eddies and their impact on near-surface chlorophyll stocks and oxygen supersaturation over the Campeche Canyon, Gulf of Mexico. Journal of Geophysical Research, 109: C05012.

Received: November 9, 2020; Accepted: April 5, 2021
Sherman, K. \& Hempel, G. 2009. Perspectives on regional seas and the large marine ecosystem approach. In: Sherman, K. \& Hempel, G. (Eds.). The UNEP large marine ecosystem report: a perspective on changing conditions in LMEs of the world's Regional Seas. United Nations Environment Programme, Nairobi, pp. 3-22.

Siegel, D.A., Doney, S.C. \& Yoder, J.A. 2002. The North Atlantic spring phytoplankton bloom and Sverdrup's critical depth hypothesis. Science, 296: 730-733.

Signoret, M., Monreal-Gómez, M.A., Aldeco, J. \& Salas de León, D.A. 2006. Hydrography, oxygen saturation, suspended particulate matter, and chlorophyll- $a$ fluorescence in an oceanic region under freshwater influence. Estuarine Coastal and Shelf Science, 69: 153-164.

Simon, N., Cras, A.L., Foulon, E. \& Lemée, R. 2009. Diversity and evolution of marine phytoplankton. Comptes Rendus Biologies, 332: 159-170.

Takao, S., Iida, T., Isada, T., Saitoh, S.I., Hirata, T. \& Suzuki, K. 2014. Bio-optical properties during the summer season in the Sea of Okhotsk. Progress in Oceanography, 26: 233-241.

Torres-Martínez, C.M., Coria-Monter, E., Salas de León, D.A., Monreal-Gómez, M.A. \& Durán-Campos, E. 2020. Hydrography and phytoplankton biomass in the Campeche Canyon and Bank, southern Gulf of Mexico, during February of 2011. Pan-American Journal of Aquatic Sciences, 15: 64-73.

Vázquez de la Cerda, A.M., Reid, R.O., DiMarco, S.F. \& Jochens, A.E. 2005. Bay of Campeche circulation: an update. In: Sturges, W. \& Lugo-Fernandez, A. (Eds.). Circulation in the Gulf of Mexico: observations and models. American Geophysical Union, Washington DC, pp. 279-293. 